\title{
Article
}

\section{Radial Extracorporeal Shockwave Therapy versus Ultrasound Therapy in Adult Patients with Idiopathic Scoliosis}

\author{
Cristina Daia ${ }^{1,2,+} \oplus$, Cristian Scheau ${ }^{3, *} *$ C) Corneliu Toader ${ }^{1,4,+}$, Ana Maria Bumbea ${ }^{5,6,+}$, \\ Visarion Danut Caimac 5,6,+, Ioana Andone ${ }^{1,2}$, Cristina Popescu 1,2, Aura Spanu 1,2 and Gelu Onose ${ }^{1,2}$ \\ 1 Department of Medical Rehabilitation, “Carol Davila" University of Medicine and Pharmacy, \\ 041914 Bucharest, Romania; cristinaoctavianadaia@gmail.com (C.D.); corneliutoader@gmail.com (C.T.); \\ ioanaandone11@yahoo.com (I.A.); cristina_popescu_recuperare@yahoo.com (C.P.); \\ aura_ko@yahoo.com (A.S.); geluonose@gmail.com (G.O.) \\ 2 Neuromuscular Department, Clinical Emergency Hospital "Bagdasar Arseni”, 041914 Bucharest, Romania \\ 3 Department of Physiology, “Carol Davila” University of Medicine and Pharmacy, 050474 Bucharest, Romania \\ 4 Department of Neurosurgery, National Institute of Cerebro-Vascular Diseases, 041914 Bucharest, Romania \\ 5 Department of Medical Rehabilitation, University of Medicine and Pharmacy, 200349 Craiova, Romania; \\ anamariabumbea@yahoo.com (A.M.B.); dcaimac@yahoo.com (V.D.C.) \\ 6 Neurorehabiltation Department, Clinical Neuropsychiatry Hospital, 200473 Craiova, Romania \\ * Correspondence: cristian.scheau@umfcd.ro \\ + These authors have contributed equally to this work and share first authorship.
}

check for

updates

Citation: Daia, C.; Scheau, C.; Toader,

C.; Bumbea, A.M.; Caimac, V.D.;

Andone, I.; Popescu, C.; Spanu, A.;

Onose, G. Radial Extracorporeal

Shockwave Therapy versus

Ultrasound Therapy in Adult Patients with Idiopathic Scoliosis. J. Clin. Med. 2021, 10, 1701. https://doi.org/

$10.3390 /$ jcm10081701

Academic Editor: Björn Gerdle

Received: 24 February 2021

Accepted: 12 April 2021

Published: 15 April 2021

Publisher's Note: MDPI stays neutral with regard to jurisdictional claims in published maps and institutional affiliations.

Copyright: (C) 2021 by the authors. Licensee MDPI, Basel, Switzerland. This article is an open access article distributed under the terms and conditions of the Creative Commons Attribution (CC BY) license (https:/ / creativecommons.org/licenses/by/ $4.0 /)$.
Abstract: Background: This study aimed to compare the effectiveness of radial extracorporeal shockwave and ultrasound therapies in adult patients with idiopathic scoliosis in terms of pain, disability, and quality of life. Methods: Forty-eight patients with idiopathic scoliosis were randomly divided into three groups of 16: shockwave, ultrasound, and control. The patients were evaluated at admission (day one) and at discharge (day 14) for pain, by using the visual analogue scale; for disability, by using the Oswestry disability index; and for the quality of life, with short form-36. Results: Radial extracorporeal shockwave therapy was more effective than ultrasound in reducing pain $(p=0.004)$ and increasing quality of life, bringing extra vitality $(p=0.003)$ and emotional comfort $(p=0.007)$ to the patient. Both shockwave therapy $(p=0.001)$ and ultrasound therapy $(p=0.003)$ were effective in reducing pain. In terms of disability, both treatments had similar effects $(p=0.439)$. Conclusion: Radial shockwave was significantly more effective than ultrasound in reducing pain and increasing the quality of life, bringing additional vitality and emotional comfort to the patient with idiopathic scoliosis. In terms of disability, both treatments had similar effects when associated with kinesitherapy.

Keywords: radial extracorporeal shockwave therapy; ultrasound therapy; adult idiopathic scoliosis; pain; quality of life; disability

\section{Introduction}

Idiopathic scoliosis is a three-dimensional spinal deviation of the spinal axis with a curvature exceeding $10^{\circ}$ on a plain anteroposterior $X$-ray image, with no other underlying disease identified to provoke it [1]. It is the most common spinal deformity that develops in otherwise healthy children [2]. A proportion of $23 \%$ to $51 \%$ of adolescents with idiopathic scoliosis had significant back pain $[2,3]$. Back pain is approximately twice as prevalent in adolescents with idiopathic scoliosis compared with non-scoliosis patients [4], and it decreases the patients' quality of life [5]. Literature data regarding pain in adults with idiopathic scoliosis are scarce; however, a main cause of pain in idiopathic scoliosis is muscle contracture, mainly located in the convexity of the spine [6]. Adults with idiopathic scoliosis have back pain generated by self-sustaining muscle contractures [7] induced by movements; hence, it is important to have an effective and secure therapeutic approach with muscle-relaxing effects such as physiotherapy procedures, as in as shockwave (SW) [7] 
or ultrasound (US) therapies [8], which are two related procedures in terms of mechanical and physical properties.

Oscillatory electro-mechanic therapy is the application of oscillation waves with high frequency and pressure, which relies on a mechanical means of propagation. In theory, this category includes ultrasonic waves and ballistic shock waves. Ultrasound is a mechanical oscillation produced by physiotherapy devices based on the inverted piezoelectric effect, which spreads within tissues with high frequencies in the range of $8 \times 10^{5}-1 \times 10^{6} \mathrm{~Hz}$ [9-11]. Therapeutic dosing of US is carried out according to power density $\left(\mathrm{W} / \mathrm{cm}^{2}\right)$, application time (minutes), and pulse application form (continuous/burst) [9-11].

Shockwaves are a complex of "high-pressure" oscillation waves that yield around 150 mega Pascals (MPa), causing real mechanical shocks in the targeted tissues. Alternate names such as "high-pressure waves", "ballistic waves", or "shockwaves" were assigned for this very reason, as they cause micro-trauma $[12,13]$. There are multiple means of producing SWs. One method is based on the electrohydraulic effect, resulting in lowpressure SWs, also known as radial shockwaves (RSW). Another manner of generating SWs relies on the electromagnetic effect, the inverted piezoelectric effect, and a spark discharge, producing high-pressure SWs, labeled focused shockwaves. Shockwave therapy dosing factors in the number of shocks, application time, frequency, energy transfer, and form of application (continuous or burst) [12].

Both US and SWs produce a mechanical impact on the target tissue, causing similar physical and chemical effects, such as heat generation, cavitation, and diffusion. The two types of waves also have common clinical effects, mainly, pain relief and muscle relaxation [14,15]. However, the pressure level at which these effects occur is different, as SWs have a pressure peak of at least 1000 times stronger than that of US [16,17]. Therefore, patient pathology plays an important role in choosing the appropriate method $[18,19]$.

The effectiveness of US and SWs has been compared in pathologies such as fibromyalgia/myofascial pain syndrome [20], plantar fasciitis [21,22], epicondylitis [23,24], and tendonitis of the shoulder [25], and no significant differences were noted in terms of alleviating pain, increasing the quality of life (using the short form-36 (SF-36)), or improving disability. In our paper, we aim to measure the effectiveness of these two treatment modalities in terms of improving the pain, disability, and quality of life in adult patients with idiopathic scoliosis.

\section{Materials and Methods}

The study comprises 48 patients diagnosed with idiopathic dorsal-lumbar scoliosis, either admitted to the hospital or benefiting from ambulatory care, between February 2019 and February 2020.

\subsection{Inclusion Criteria}

- $\quad$ Patients over 30 years old;

- Low back dorsal-lumbar nonspecific musculoskeletal pain;

- Diagnosed with dorsal-lumbar idiopathic scoliosis of any type (mild, moderate, or severe) and any degree of curvature from 10 to 60 degrees.

\subsection{Exclusion Criteria}

Our study employed the classical contraindications for any electrotherapy procedure [7]:

- Idiopathic scoliosis that required surgery intervention;

- Any vertebral or spinal bone marrow pathology other than idiopathic scoliosis: disc herniation, spinal cord injury, benign or malignant tumors, and so on;

- Fever, regardless of the cause;

- Acute or decompensated diseases, regardless of their nature: infectious, inflammatory, cardiovascular, respiratory, neurological, rheumatological, metabolic, and so on;

- Uncontrolled hypertension with systolic blood pressure higher than $150 \mathrm{mmHg}$; 
- Any mental disorder;

- Any neoplasm;

- Osteosynthesis materials or other metals in the area of application;

- Patients carrying a cardiac pacemaker;

- $\quad$ Pregnant women, women during menstruation, women with intrauterine devices (IUD);

- Patients with altered general condition or cachexia;

- $\quad$ Patients with any pathology that could generate a disability other than idiopathic scoliosis;

- Patients with any type of idiopathic scoliosis other than dorsal-lumbar;

- $\quad$ Patients with any pain other than low-back dorsal-lumbar pain.

\subsection{Study Design}

In our study, we used block randomization to obtain three balanced groups. We set block randomization for gender (male and female), scoliosis type (dorsal and lumbar; then, left and right curvatures), curves in degree categories (0-10, 11-20, 21-30, 31-40, 41-50, 51-60), and age groups (30-40, 41-50, 51-60, 61-70, 71-80) (Table 1). We balanced the number of subjects in each block in order to increase the comparability between the groups.

Table 1. Patient characteristics in the three study lots regarding scoliosis type, degree, and severity.

\begin{tabular}{|c|c|c|c|c|c|c|c|c|c|c|c|}
\hline \multicolumn{4}{|c|}{ RSWT $^{1}$ Lot } & \multicolumn{4}{|c|}{ UST $^{2}$ Lot } & \multicolumn{4}{|c|}{ Control Lot } \\
\hline $\begin{array}{c}\text { Patient } \\
\text { No. }\end{array}$ & $\begin{array}{l}\text { Dorsal } \\
\text { Lumbar } \\
\text { Scoliosis } \\
\text { Type }\end{array}$ & $\begin{array}{l}\text { Degree } \\
\text { Curve }\end{array}$ & $\begin{array}{l}\text { Severity } \\
\text { Type }^{3}\end{array}$ & $\begin{array}{c}\text { Patient } \\
\text { No. }\end{array}$ & $\begin{array}{l}\text { Dorsal } \\
\text { Lumbar } \\
\text { Scoliosis } \\
\text { Type }\end{array}$ & $\begin{array}{l}\text { Degree } \\
\text { Curve }\end{array}$ & $\begin{array}{l}\text { Severity } \\
\text { Type }^{3}\end{array}$ & $\begin{array}{c}\text { Patient } \\
\text { No. }\end{array}$ & $\begin{array}{l}\text { Dorsal } \\
\text { Lumbar } \\
\text { Scoliosis } \\
\text { Type }\end{array}$ & $\begin{array}{c}\text { Degree } \\
\text { Curve }\end{array}$ & $\begin{array}{l}\text { Severity } \\
\text { Type }^{3}\end{array}$ \\
\hline 1 & left & 35 & moderate & 17 & left & 32 & moderate & 33 & left & 50 & severe \\
\hline 2 & right & 55 & severe & 18 & left & 20 & mild & 34 & left & 30 & moderate \\
\hline 3 & left & 38 & moderate & 19 & right & 38 & moderate & 35 & left & 20 & mild \\
\hline 4 & right & 38 & moderate & 20 & right & 32 & moderate & 36 & right & 35 & moderate \\
\hline 5 & right & 38 & moderate & 21 & right & 55 & severe & 37 & right & 55 & severe \\
\hline 6 & left & 50 & severe & 22 & right & 35 & moderate & 38 & right & 50 & severe \\
\hline 7 & right & 35 & moderate & 23 & right & 55 & severe & 39 & right & 22 & mild \\
\hline 8 & right & 18 & mild & 24 & left & 30 & moderate & 40 & right & 35 & moderate \\
\hline 9 & left & 20 & mild & 25 & left & 48 & severe & 41 & left & 45 & severe \\
\hline 10 & left & 50 & severe & 26 & left & 50 & severe & 42 & left & 50 & severe \\
\hline 11 & left & 45 & severe & 27 & right & 22 & mild & 43 & right & 38 & moderate \\
\hline 12 & left & 30 & moderate & 28 & right & 38 & moderate & 44 & right & 30 & moderate \\
\hline 13 & right & 50 & severe & 29 & left & 36 & moderate & 45 & left & 38 & moderate \\
\hline 14 & right & 35 & moderate & 30 & left & 50 & severe & 46 & left & 32 & moderate \\
\hline 15 & right & 55 & severe & 31 & right & 30 & moderate & 47 & right & 38 & moderate \\
\hline 16 & right & 30 & moderate & 32 & right & 50 & severe & 48 & right & 50 & severe \\
\hline
\end{tabular}

${ }^{1}$ RSWT $=$ radial extracorporeal shockwave treatment. ${ }^{2}$ UST $=$ ultrasound treatment. ${ }^{3}$ Severity type: mild, $10-25$; moderate, 26-40; and severe, over 40 [26].

Group A $(n=16)$ received US treatment (UST), applied bilaterally in the paravertebral dorsal-lumbar region. The regimen was $0.5 \mathrm{~W} / \mathrm{cm}^{2}$, for $5 \mathrm{~min}$, using continuous emission, dynamic application in a slow rhythm, and daily application rhythm over a total of 10 sessions. Group B $(n=16)$ received RSW treatment (RSWT) to the paravertebral dorsallumbar area using a pressure of $0.2 \mathrm{MPa}$ (2 Barr) in addition to a series of 2000 shocks in pulse emission (BURST mode) with a frequency of $10 \mathrm{~Hz}$ and an average energy transfer of $0.4 \mathrm{~m} \mathrm{~J} / \mathrm{mm}^{2}$ for a duration of $4.48 \mathrm{~min}$. The application rate was every two days with a total of five sessions. Radial extracorporeal shockwave therapy was delivered every two days in order to avoid microtrauma cumulating effects. Group C $(n=16)$ was the control group and did not receive physiotherapy. The total treatment time was 14 days. 


\subsection{Patient Rehabilitation Management}

Each patient signed a detailed informed consent. The study respects the ethical principles for research presented in the Declaration of Helsinki. All patients included in this study underwent adequate treatment in compliance with ethical guidelines, standing good practices, and associated comorbidities. All patients benefited from the same kinesitherapy procedures as part of the rehabilitation program. The kinesitherapy program was provided by a kinetotherapist and consisted of a sum of specific exercises named the Klapp method [27]. All patients benefited from the same exercise program, applied daily for the same period of 10 days, 60 min per day.

\subsection{Patient Evaluation}

All patients were evaluated according to the national protocol of evaluation in nontraumatic spine pathologies [28]. The clinical and paraclinical evaluation consists of recording and describing six specific syndromes through various diagnostic methods: (1) spinal, active, and passive (posture and radiography); (2) muscle (contracture, ultrasonography [29]); (3) radicular (neurologic examination and MRI); (4) spinal cord (neurologic examination); (5) psychological (psychological examination); and (6) functional (disability evaluation) [28]. The pain experienced by the patients in our study was caused by muscle contraction, and this was a criterion for enrollment in this study. The kinesitherapy program was administrated concomitant with the interventions, for all groups.

\subsection{Evaluated Parameters}

For all groups, the total time for evaluation was 14 days. The following parameters were assessed:

1. Pain: using the visual analogue scale (VAS), which highlights 10 degrees of pain from 0 (no pain) to 10 points (the most severe pain) [30]. The VAS scale was performed on days 1 and 14 for all patients, before and after the application of US and RSW for the study groups.

2. Disability: using the Oswestry disability index (ODI). The ODI scale was performed on days 1 and 14 for all patients [31].

3. Quality of life (QoL): using short form-36 (SF-36), which consists of 8 subscales with 36 items that evaluate the physical, social, and usual activity limitations due to physical or emotional problems, bodily pain, mental health, vitality, and general health perceptions [32]. The QoL survey was performed only on day 14 for all patients.

\subsection{Statistical Analysis}

SPSS Statistics for Windows version 15.0 (SPSS Inc., Chicago, IL, USA) was used for statistical analysis. The distribution of patient demographic features was analyzed using descriptive statistical methods. Population normality was assessed using the KolmogorovSmirnov test. Levene's test for equality of variances, $t$-test for equality of means, the Mann-Whitney test, and the Wilcoxon test were used for comparison of parameters. The Tamhane post hoc evaluation was employed after multiple comparisons were performed by ANOVA when equal variances were not assumed. Pearson's chi-squared test was used for comparing categorical data. The statistical significance of $p$-value was considered $p<0.05$. For the Kolmogorov-Smirnov test, $p$-value was considered $p>0.2$.

\section{Results}

The demographic analysis of the study groups showed that the patients were similar in terms of age ( $\mathrm{F}=0.07$, sig. 0.926, ANOVA) and gender ( 0.182 Pearson chi-square, sig. 0.913) distribution (Table 2). 
Table 2. Demographic data of age and gender.

\begin{tabular}{|c|c|c|c|c|c|c|c|c|}
\hline \multirow{2}{*}{ Lot } & \multicolumn{6}{|c|}{ Demographic Data of Age } & \multicolumn{2}{|c|}{ Demographic Data of Gender } \\
\hline & $n$ & Median & Mean & Min & Max & Std. Dev & Female Number & Male Number \\
\hline RSWT $^{1}$ & 16 & 46.50 & 51 & 31 & 78 & 14.43 & 10 & 6 \\
\hline UST $^{2}$ & 16 & 51.00 & 51 & 32 & 74 & 12.18 & 11 & 5 \\
\hline Control & 16 & 47.00 & 50 & 36 & 74 & 12.21 & 10 & 6 \\
\hline Total & 48 & 50.85 & 51 & 31 & 78 & 12.72 & 31 & 17 \\
\hline
\end{tabular}

${ }^{1}$ RSWT $=$ radial extracorporeal shockwave treatment. ${ }^{2}$ UST $=$ ultrasound treatment.

The analysis of the initial VAS in all lots shows similar values (0.485, ANOVA; 0.963 , Tamhane post hoc). The evaluation of pain on the VAS scale shows that the average differences in the final VAS (compared with the initial score) were significantly lower in the RSWT lot $(-6.38 \pm 1.02)$ compared with the UST lot $(-5.38 \pm 0.71)$ and the control group $(-4.50 \pm 0.62)$, with a statistical significance of $p<0.001$ and $p=0.004$, respectively (Mann-Whitney). The difference in the VAS score was also significantly lower in the UST patients compared with the control patients (Table 3).

Table 3. Pain and disability index reported using the VAS and ODI questionnaire.

\begin{tabular}{|c|c|c|c|c|c|c|c|}
\hline \multirow{2}{*}{\multicolumn{2}{|c|}{ Test Parameters }} & \multicolumn{3}{|c|}{ VAS ${ }^{1}$ Evolution } & \multicolumn{3}{|c|}{ ODI $^{2}$ Evolution } \\
\hline & & RSWT Lot & UST Lot & Control Lot & RSWT $^{3}$ Lot & UST $^{4}$ Lot & Control Lot \\
\hline \multicolumn{2}{|c|}{ No. } & 16 & 16 & 16 & 16 & 16 & 16 \\
\hline \multirow{2}{*}{$\begin{array}{c}\text { Normal } \\
\text { Parameters }\end{array}$} & Mean & -6.38 & -5.38 & & -28.06 & -29.56 & -27.31 \\
\hline & Std. Deviation & 1.025 & 0.719 & & 4.328 & 6.293 & 4.743 \\
\hline \multirow{3}{*}{$\begin{array}{c}\text { Most Extreme } \\
\text { Differences }\end{array}$} & Absolute & 0.232 & 0.308 & & & & \\
\hline & Positive & 0.232 & 0.308 & & & & \\
\hline & Negative & -0.205 & -0.199 & & & & \\
\hline \multicolumn{2}{|c|}{ Kolmogorov-Smirnov Z } & 0.929 & 1.231 & & & & \\
\hline \multicolumn{2}{|c|}{ Asymp. Sig. (2-tailed) } & 0.354 & 0.097 & & & & \\
\hline \multicolumn{2}{|c|}{ Mann-Whitney U test mean rank } & 9.53 & 11.69 & 21.31 & & & \\
\hline \multicolumn{2}{|c|}{ Asymp. Sig. (2-tailed) } & 0.000 & 0.002 & & & & \\
\hline \multicolumn{2}{|c|}{ Exact Sig. $(2 \times(1$-tailed Sig. $))$} & 0.000 & 0.003 & & & & \\
\hline \multicolumn{2}{|c|}{ ANOVA Sig. } & & & & & 0.465 & \\
\hline \multicolumn{2}{|c|}{ Tamhane Sig. } & & & & 0.823 & 0.823 & 0.955 \\
\hline
\end{tabular}

${ }^{1}$ VAS $=$ visual analogue scale. ${ }^{2}$ ODI $=$ Oswestry disability index. ${ }^{3}$ RSWT $=$ radial shockwaves treatment. ${ }^{4}$ UST $=$ ultrasound treatment.

The analysis of the initial ODI in all lots shows a comparable value (0.465 ANOVA, and 0.981 Tamhane post hoc). Regarding the evaluation of disability using ODI (highlights), the average of the differences between the final and the initial ODI in the RSWT group $(-28.06 \pm 4.32)$ did not differ significantly from that of the UST group $(-29.56 \pm 6.29)$ or the control group $(-27.31 \pm 4.743)(p=0.361$ Mann-Whitney, $p=0.439$, ANOVA, post hoc Tamhane 0.955).

Regarding the QoL, the SF-36 subscales showed significantly better values for the following parameters: vitality (means 21.22 versus $11.78 ; p=0.003$ ) and emotional component (means 20.84 versus 12.16; $p=0.007$ ) in the RSWT group versus UST; no other statistically significant differences were noted (Table 4 ). 
Table 4. Quality of life, short form-36, subscales RSWT versus UST lots-Mann-Whitney and Wilcoxon tests.

\begin{tabular}{cccccccc}
\hline Statistic Test & $\begin{array}{c}\text { General } \\
\text { Health }\end{array}$ & $\begin{array}{c}\text { Physical } \\
\text { Functioning }\end{array}$ & Bodily Pain & Physical Role & Vitality & $\begin{array}{c}\text { Role } \\
\text { Emotional }\end{array}$ & $\begin{array}{c}\text { Social } \\
\text { Functioning }\end{array}$ \\
\hline Mann-Whitney U & 111.500 & 85.500 & 109.500 & 98.000 & 52.500 & 58.500 & 76.000 \\
\hline Wilcoxon W & 247.500 & 221.500 & 245.500 & 234.000 & 188.500 & 194.500 & 212.000 \\
\hline Z & -0.626 & -1.624 & -0.710 & -1.154 & -2.865 & -2.648 & -2.000 \\
\hline Asymp. Sig. (2-tailed) & 0.531 & 0.104 & 0.478 & 0.249 & 0.004 & 0.008 & 0.046 \\
\hline Exact Sig. [2 $\times$ (1-tailed Sig.)] & 0.539 & $0.110^{\text {a }}$ & 0.491 & 0.270 & 0.003 & 0.007 & 0.051 \\
\hline & & ${ }^{a}$ Not corrected for ties. Grouping variable: TTip. & &
\end{tabular}

No significant immediate or delayed adverse reactions were observed following the physiotherapy procedures.

\section{Discussion}

In this study, we used five large block randomizations to increase the comparability between groups by keeping the ratio of the number of subjects between them almost the same. Consequently, the risk of selection bias was increased as the treatment of the subject in the block was known. Because we analyzed a new physiotherapy treatment, we chose this type of randomization in order to recognize its therapeutic benefits, starting from similar lots, to the best of our ability [33]. Although randomization minimizes the selection bias in this case-control study, it was not a blinded intervention; therefore, another limitation of this study was allowing the subsequent differential cointerventions or biased assessment of outcomes [34]. The number of cases in the analyzed groups is low; therefore, the results we share through this study should be considered as indicative while encouraging subsequent research to verify them on larger populations. For the symptomatic treatment of idiopathic scoliosis, we chose to compare two methods of physiotherapy with similar features, as they both rely on mechanical waves. Participants had low-back muscle pain caused by prolonged muscle contracture, especially from the convexity of scoliosis. Patients had no headache, sore areas, spinal pain, generalized pain, or of any other type. The selection of a clear type of pain (muscle contraction pain), due to a specific type of idiopathic scoliosis (dorsal-lumbar scoliosis), could be another limitation of the antalgic potential of the proposed physiotherapy: RSWT and UST. On the other hand, we demonstrated that RSWT and UST have significant statistical antalgic effects acting on muscle contractures; therefore, we can recommend this kind of physiotherapy for this specific kind of pain. The main limitation of this study should be considered the lack of a standard protocol regarding RSWT and UST in scoliosis. To our knowledge, this is one of the first studies in the field, and the results appear promising. However, more studies on a larger number of patients are needed to confirm these results. Another limitation is the short-term evaluation of the outcomes assessed in the study. In our view, a follow-up examination would be the next step to be addressed in further studies.

Analyzing the results, we observed that RSWT produces a statistically significant decrease in pain generated by idiopathic scoliosis versus UST. It should be noted, however, that both treatments determined an average decrease in the VAS score for pain: UST by 5.38 points, and RSWT by 6.38 points, respectively; however, RSWT proved to be statistically more effective and was further followed by a significantly higher state of emotional comfort and vitality according to the analysis of the patients' QoL. Regarding the rest of the parameters analyzed in SF-36, we did not detect any other statistically significant differences. The mental health component of QoL SF-36 was not analyzed because the presence of mental illness was considered an exclusion criterion in our study; moreover, according to literature data, mental health factors do not influence QoL SF-36 in patients with scoliosis [35]. Radial extracorporeal shockwave therapy has been demonstrated to have a significant influence on the reduction of pain in patients with chronic low-back pain [36]. The statistically proven superior analgesic effect of RSWT may be explained by its 
particular mechanism of destroying unmyelinated sensory fibers [37] added to fibrinolytic properties [38] when compared to UST [39], determining the lysis of fibrin bridges in long-lasting scoliosis contractures, while also enabling effective muscle relaxation and subsequent participation in movement.

Regarding the disability induced by idiopathic scoliosis in adults [40], which was investigated in our study using ODI, there were no statistically significant differences in its improvement after therapy. This finding is consistent with the fact that all patients benefited from a similar kinetic program, an element with an essential role in terms of patient functionality [41].

Both types of physiotherapy were very well-tolerated by patients, who showed no side effects; therefore, we recommend both methods in terms of safety and tolerability profile.

\section{Conclusions}

After a short-term evaluation, radial extracorporeal shockwave therapy and ultrasound therapy were both effective in reducing pain due to muscle contraction in adult patients with idiopathic scoliosis; however, RSWT had statistically superior effects in reducing pain and increasing the quality of life, as well as bringing additional vitality and emotional comfort to the patients. In terms of disability, both treatments have similar effects when associated with kinesitherapy. Both types of physiotherapy are safe and well-tolerated by patients with idiopathic scoliosis. Further studies involving larger study groups and follow-up examinations are needed in order to extend and confirm our reported findings, as well as to develop appropriate standardized protocols for these types of patients.

Author Contributions: Conceptualization: C.D., C.T., V.D.C., G.O.; methodology: C.D., C.T., V.D.C.; formal analysis and investigation: A.M.B.; writing-original draft preparation: C.D., C.T., V.D.C., I.A., C.P., A.S.; writing—review and editing: C.D., C.T., V.D.C., C.S.; resources: A.M.B., C.S.; supervision: G.O. All authors have read and agreed to the published version of the manuscript.

Funding: This research received no external funding.

Institutional Review Board Statement: This study has been approved by the Ethics Commission of the Clinical Neuropsychiatry Hospital, Craiova, Romania and Clinical Emergency Hospital “Bagdasar Arseni", Bucharest, Romania, Identification No.39309.

Informed Consent Statement: Informed consent was obtained from all subjects involved in the study.

Data Availability Statement: The data sets used and analyzed during the current study are available from the corresponding author upon reasonable request. The data are not publicly available due to privacy reasons.

Acknowledgments: We would like to thank T. Spircu for his assistance with statistics and data interpretation. Additionally, we thank Toma Gheorghe for his support and dedication in aiding patient recovery in the field of physio- and kinesi-therapy.

Conflicts of Interest: The authors declare no conflict of interest.

\section{References}

1. Trobisch, P.; Suess, O.; Schwab, F. Idiopathic scoliosis. Dtsch. Arztebl. Int. 2010, 107, 875-884. [CrossRef]

2. Choudhry, M.N.; Ahmad, Z.; Verma, R. Adolescent Idiopathic Scoliosis. Open Orthop. J. 2016, 10, 143-154. [CrossRef]

3. Jackson, R.P.; Simmons, E.H.; Stripinis, D. Incidence and severity of back pain in adult idiopathic scoliosis. Spine 1983, 8, 749-756. [CrossRef]

4. Théroux, J.; Le May, S.; Fortin, C.; Labelle, H. Prevalence and management of back pain in adolescent idiopathic scoliosis patients: A retrospective study. Pain Res. Manag. 2015, 20, 153-157. [CrossRef]

5. Makino, T.; Kaito, T.; Kashii, M.; Iwasaki, M.; Yoshikawa, H. Low back pain and patient-reported QOL outcomes in patients with adolescent idiopathic scoliosis without corrective surgery. Springerplus 2015, 4, 397. [CrossRef]

6. Alves, D.P.L.; de Araújo, B. Muscle disorders in adolescent idiopathic scoliosis: Literature review. Coluna/Columna 2016, 15, 73-77. [CrossRef]

7. Daia, C.; Onose, G. Towards a new indication for extracorporeal shock wave therapy: Idiopathic scoliosis. Proc. Rom. Acad. Ser. B 2017, 19, 171-176. 
8. Janicki, J.A.; Alman, B. Scoliosis: Review of diagnosis and treatment. Paediatr. Child Health 2007, 12, 771-776. [CrossRef] [PubMed]

9. Miller, D.L.; Smith, N.B.; Bailey, M.R.; Czarnota, G.J.; Hynynen, K.; Makin, I.R.; Bioeffects Committee of the American Institute of Ultrasound in Medicine. Overview of therapeutic ultrasound applications and safety considerations. J. Ultrasound Med. 2012, 31, 623-634. [CrossRef]

10. Chapelon, J.Y.; Cathignol, D.; Cain, C.; Ebbini, E.; Kluiwstra, J.U.; Sapozhnikov, O.A.; Fleury, G.; Berriet, R.; Chupin, L.; Guey, J.L. New piezoelectric transducers for therapeutic ultrasound. Ultrasound Med. Biol. 2000, 26, 153-159. [CrossRef]

11. Robertson, J.V. Dosage and treatment response in randomized clinical trials of therapeutic ultrasound. Phys. Ther. Sport 2012, 3, 124-133. [CrossRef]

12. Van der Worp, H.; Van den Akker-Scheek, I.; Van Schie, H.; Zwerver, J. ESWT for tendinopathy: Technology and clinical implications. Knee Surg. Sports Traumatol. Arthrosc. 2013, 21, 1451-1458. [CrossRef] [PubMed]

13. Reilly, J.M.; Bluman, E.; Tenforde, A.S. Effect of Shockwave Treatment for Management of Upper and Lower Extremity Musculoskeletal Conditions: A Narrative Review. PM R 2018, 10, 1385-1403. [CrossRef] [PubMed]

14. Ebadi, S.; Henschke, N.; Forogh, B.; Nakhostin Ansari, N.; van Tulder, M.W.; Babaei-Ghazani, A.; Fallah, E. Therapeutic ultrasound for chronic low back pain. Cochrane Database Syst. Rev. 2020, 7, CD009169. [CrossRef]

15. Zhang, L.; Fu, X.B.; Chen, S.; Zhao, Z.B.; Schmitz, C.; Weng, C.S. Efficacy and safety of extracorporeal shock wave therapy for acute and chronic soft tissue wounds: A systematic review and meta-analysis. Int. Wound J. 2018, 15, 590-599. [CrossRef]

16. Izadifar, Z.; Babyn, P.; Chapman, D. Mechanical and Biological Effects of Ultrasound: A Review of Present Knowledge. Ultrasound Med. Biol. 2017, 43, 1085-1104. [CrossRef] [PubMed]

17. Notarnicola, A.; Moretti, B. The biological effects of extracorporeal shock wave therapy (eswt) on tendon tissue. Muscles Ligaments Tendons J. 2012, 2, 33-37. [PubMed]

18. Morishita, K.; Karasuno, H.; Yokoi, Y.; Morozumi, K.; Ogihara, H.; Ito, T.; Hanaoka, M.; Fujiwara, T.; Fujimoto, T.; Abe, K. Effects of therapeutic ultrasound on range of motion and stretch pain. J. Phys. Ther. Sci. 2014, 26, 711-715. [CrossRef]

19. Dedes, V.; Stergioulas, A.; Kipreos, G.; Dede, A.M.; Mitseas, A.; Panoutsopoulos, G.I. Effectiveness and Safety of Shockwave Therapy in Tendinopathies. Mater. Sociomed. 2018, 30, 131-146. [CrossRef]

20. Aktürk, S.; Kaya, A.; Çetintaş, D.; Akgöl, G.; Gülkesen, A.; Kal, G.A.; Güçer, T. Comparision of the effectiveness of ESWT and ultrasound treatments in myofascial pain syndrome: Randomized, sham-controlled study. J. Phys. Ther. Sci. 2018, 30, 448-453. [CrossRef]

21. Dedes, V.; Tzirogiannis, K.; Polikandrioti, M.; Dede, A.M.; Nikolaidis, C.; Mitseas, A.; Panoutsopoulos, G.I. Radial Extra Corporeal Shockwave Therapy Versus Ultrasound Therapy in the Treatment of Plantar Fasciitis. Acta Inform. Med. 2019, 27, 45-49. [CrossRef]

22. Greve, J.M.A.; Grecco, M.V.; Santos-Silva, P.R. Comparison of Radial Shockwaves and Conventional Physiotherapy for Treating Plantar Fasciitis. Clinics 2009, 64, 97-103. [CrossRef]

23. Yalvaç, B.; Mesci, N.; Külcü, D.G.; Yurdakul, O.V. Comparison of ultrasound and extracorporeal shock wave therapy in lateral epicondylosis. Acta Orthop. Traumatol. Turc. 2018, 52, 357-362. [CrossRef] [PubMed]

24. Dedes, V.; Tzirogiannis, K.; Polikandrioti, M.; Dede, A.M.; Mitseas, A.; Panoutsopoulos, G.I. Comparison of radial extracorporeal shockwave therapy with ultrasound therapy in patients with lateral epicondylitis. J. Med. Ultrason. 2020, 47, 319-325. [CrossRef] [PubMed]

25. De Boer, F.A.; Mocking, F.; Nelissen, E.M.; Van Kampen, P.M.; Huijsmans, P.E. Ultrasound guided Needling vs. Radial Shockwave Therapy in calcific tendinitis of the shoulder: A prospective randomized trial. J. Orthop. 2017, 14, 466-469. [CrossRef]

26. Barrios, C.; Pérez-Encinas, C.; Maruenda, J.I.; Laguía, M. Significant ventilatory functional restriction in adolescents with mild or moderate scoliosis during maximal exercise tolerance test. Spine 2005, 30, 1610-1615. [CrossRef] [PubMed]

27. Dantas, D.D.; De Assis, S.J.; Baroni, M.P.; Lopes, J.M.; Cacho, E.W.; Cacho, R.D.; Pereira, S.A. Klapp method effect on idiopathic scoliosis in adolescents: Blind ran-domized controlled clinical trial. J. Phys. Ther. Sci. 2017, 29, 1-7. [CrossRef] [PubMed]

28. Onose, G. National Platform of Medical Guides in Physical Medicine and Rehabilitation: Evaluation Guide in Physical Medicine and Rehabilitation; Onose, G., Ed.; "Carol Davila" University Publishing House: Bucharest, Romania, 2011.

29. Ma, C.Z.; Ren, L.J.; Cheng, C.L.; Zheng, Y.P. Mapping of Back Muscle Stiffness along Spine during Standing and Lying in Young Adults: A Pilot Study on Spinal Stiffness Quantification with Ultrasound Imaging. Sensors 2020, 20, 7371. [CrossRef]

30. Haefeli, M.; Elfering, A. Pain assessment. Eur. Spine J. 2006, 15 (Suppl. 1), S17-S24. [CrossRef] [PubMed]

31. Fairbank, J.C.; Pynsent, P.B. The Oswestry Disability Index. Spine 2000, 25, 2940-2952, discussion 2952. [CrossRef]

32. Lins, L.; Carvalho, F.M. SF-36 total score as a single measure of health-related quality of life: Scoping review. SAGE Open Med. 2016, 4, 2050312116671725. [CrossRef]

33. Lim, C.Y.; In, J. Randomization in clinical studies. Korean J. Anesthesiol. 2019, 72, 221-232, Erratum in 2019, 72, 396. [CrossRef]

34. Karanicolas, P.J.; Farrokhyar, F.; Bhandari, M. Practical tips for surgical research: Blinding: Who, what, when, why, how? Can J Surg. 2010, 53, 345-348.

35. Schwab, F.; Dubey, A.; Pagala, M.; Gamez, L.; Farcy, J.P. Adult scoliosis: A health assessment analysis by SF-36. Spine 2003, 28, 602-606. [CrossRef] [PubMed]

36. Walewicz, K.; Taradaj, J.; Rajfur, K.; Ptaszkowski, K.; Kuszewski, M.T.; Sopel, M.; Dymarek, R. The Effectiveness of Radial Extracorporeal Shock Wave Therapy in Pa-tients With Chronic Low Back Pain: A Prospective, Randomized, Single-Blinded Pilot Study. Clin. Interv. Aging. 2019, 14, 1859-1869. [CrossRef] 
37. Li, S.; Wang, K.; Sun, H.; Luo, X.; Wang, P.; Fang, S.; Chen, H.; Sun, X. Clinical effects of extracorporeal shock-wave therapy and ultrasound-guided local corticosteroid injections for plantar fasciitis in adults: A meta-analysis of randomized controlled trials. Medicine 2018, 97, e13687. [CrossRef] [PubMed]

38. Frairia, R.; Berta, L. Biological effects of extracorporeal shock waves on fibroblasts. A Review. Muscles Ligaments Tendons J. 2012, 1, 138-147.

39. Cherniavsky, E.A.; Strakha, I.S.; Adzerikho, I.E.; Shkumatov, V.M. Effects of low frequency ultrasound on some properties of fibrinogen and its plasminolysis. BMC Biochem. 2011, 12, 60. [CrossRef] [PubMed]

40. Kotwal, S.; Pumberger, M.; Hughes, A.; Girardi, F. Degenerative scoliosis: A review. HSS J. 2011, 7, 257-264. [CrossRef]

41. Shu-Yan, N.; Tsz-Ki, H.; Yin-Ling, N. Physical Rehabilitation in the Management of Symptomatic Adult Scoliosis, Different Areas of Physiotherapy, Mintaze Kerem Gunel, IntechOpen. Available online: https:/ / www.intechopen.com/books/different-areas-ofphysiotherapy/physical-rehabilitation-in-the-management-of-symptomatic-adult-scoliosis (accessed on 7 April 2021). 